\title{
Chega de diversão!
}

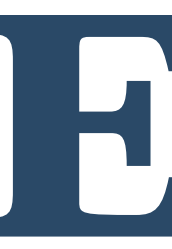

m plena era da inteligência emocional, das equipes motivadas, da flexibilidade e outras modas de fácil apelo e duvidosa eficácia, uma alemã prega o retorno da disciplina, da austeridade e da aplicação de rígidos valores morais no ambiente organizacional. Defendendo o fim do trabal ho em equipe, das jornadas flexíveis e das estruturas sem chefe, a autora Judith M air causa controvérsia. Este artigo investiga suas idéias e revela, além da polêmica, doses bem-vindas de bom senso e consistência.

por Pedro Fernando Bendassolli USP

U ma velha máxima psicanalítica afirma que uma reação forte contra um dado curso de coisas pode revelar, na verdade, um profundo medo de tal estado de coisas. Pode também revelar uma aceitação radical, só que ao inverso, desse mesmo estado de coisas. Por exemplo, quando gostamos muito de alguém, e, por algum moti- vo sério, passamos a odiar essa pessoa, tal ódio é, no fundo, uma maneira de enganarmos a nós próprios sobre o fato de que gostamos demais da referida pessoa e de que não admitimos perdê-la. Uma forte negação também pode revelar nossa recusa em aceitar certas condições ou situações. 
Psicologismos à parte, desde o final do ano passado um livro - bem como uma autora - vem causando um certo mal-estar entre gurus de gestão. Exprimindo o que talvez muitos desejem falar, mas por desinteresse ou por falta de coragem não falam, Judith Mair, sócia de uma agência de publicidade alemã, lançou um conjunto polêmico de idéias contra alguns dos mais caros dogmas da gestão de recursos humanos em seu livro Schluss mit lusting ("Chega de diversão").

Rompendo com a maioria das correntes "humanistas" de gestão de pessoas, para as quais o trabal ho deve ser fonte constante de prazer e convivência, Judith Mair defende a volta de valores rígidos de disciplina e austeridade em uma era que se vangloria de ter trazido a alma do trabalhador para 0 ambiente de trabalho. 0 livro e sua autora certamente representam um sintoma desesperado de negação do faz-de-conta criado em torno da gestão de pessoas, com seus princípios de boa vivência, horário flexível, motivação e prazer no trabalho. tortura, e, portanto, estava vinculado a dor, sofrimento e sacrifício. 0 termo vem do latim "tripalium", um antigo instrumento romano de tortura, formado por um tripé de estacas sobre 0 qual eram supliciadas pessoas ou animais.

À época de Frederick Taylor, esse sentido ainda parecia mantido: o "pai da administração científica" considerava que os trabalhadores deveriam ser adestrados e disciplinados, e seu comportamento rigorosamente controlado. Porém, com o tempo, outros significados foram sendo acrescentad os à palavra, e hoje também a vinculamos a prazer, satisfação e realização pessoal.

Uma das quatro teses de Judith Mair é de que o trabalho não é, nem deve ser, fonte de prazer ou satisfação. Segundo ela, a confusão entre trabalho e vida pessoal é uma das principais causas de frustração e estresse para os profissionais. "É um absurdo valorizar o trabal ho como um substituto para o lar ou como um símbolo de status que promete auto-real ização e diversão. Trabalho é apenas trabalho, e é exatamente isso que ele precisa voltar a ser", afirmou Mair em depoimento à revista Business World, em edição de julho de 2003.

A tese não é nova. As fronteiras princi pais causas de frustração e estresse

\section{A dificuldade em administrar o conflito} entre trabal ho e vida pessoal é uma das

\section{entre executivos e outros profissionais.} entre executivos eoutros profissionais.

No entanto, 0 aparente absurdo pode ser boa fonte de reflexão. A partir das idéias de Mair é possível desmontar o frágil discurso e as frágeis práticas que se tornaram marca registrada da gestão de recursos humanos nos últimos anos. Na raiz da questão, um fato simples: as mais populares panacéias dos últimos anos, que prometiam tanto aumentar a produtividade quanto tornar o trabal ho mais recompensador, na verdade, podem ter causado efeito inverso.

A volta de Taylor? Talvez nem todos saibam, mas o significado original da palavra "trabalho" é diametralmente oposto ao significado que Ihe damos hoje. Originalmente, trabalho significava uma forma de
Hoje, com o desenvolvimento das tecnologias da vida cotidiana, a situação tornou-se crítica: celulares, pagers, palm tops, lap tops e e-mails asseguram que o indivíduo possa ser localizado em qualquer lugar, a qualquer hora e em qualquer circunstância. A esfera privada, demarcada pelos afazeres do lar, foi invadida pelos dispositivos de acesso, permitindo um estado de permanente prontidão e total disposição ao trabalho.

Mair contrapôs na prática essa tendência: em sua agência é terminantemente proibido levar trabal ho para casa. Além disso, a convivência social limita-se ao mínimo necessário: nada de intermináveis sessões destinadas à formação de equipes, brainstormings e conversas em torno das máquinas de café. Tais atividades, se- 
gundo a alemã, servem apenas para desperdiçar tempo e para sobrecarregar desnecessariamente os funcionários. "É perigoso se trabalho e tempo livre se misturam. É um sistema totalitário se meu chefe organiza minha vida inteira, desde meu café da manhã até meu condicionamento físico. Eu quero ser o dono de meu próprio tempo livre", afirma Mair à Business World.

Pressionadas pela necessidade de status, prestígio ou poder financeiro, as pessoas entregam-se a verdadeiras sessões de tortura psíquica no trabalho. A ação de Mair, de limitar o trabalho ao exercício de uma atividade estrita de produção de coisas ou idéias, pode ser entendida como um "basta" ao tipo de postura "gulosa" e absorvente das organizações contemporâneas.

Flexibilidade questionada. 0 segundo alvo de Mair é a jornada flexível de trabalho, uma prática geralmente comemorada como importante trunfo para conseguir melhores índices de produtividade. Segundo a alemã, a jornada flexível serve apenas para mascarar o fato de que nunca as pessoas trabal haram tanto como agora.
Em sua empresa, há fronteiras claras em relação ao início e término do expediente: das $9 \mathrm{~h}$ da manhã às $6 \mathrm{~h}$ da tarde. Claro, diz Mair, que as circunstâncias podem justificar rearranjos, mas esse intervalo deve funcionar como parâmetro de orientação. "Desde que começamos a trabalhar unicamente das $9 \mathrm{~h}$ às $18 \mathrm{~h}$ nosso trabal ho tornouse mais efetivo e nossos finais de semana têm sido livres", afirma ela em entrevista à revista Amanhã, em edição de agosto de 2003. Segundo sua lógica, o fato de os profissionais trabalharem dentro desse intervalo gera maior motivação e concentração, e o tempo é aproveitado de forma mais produtiva. Com isso, sobra mais tempo para a vida pessoal, fora do trabalho.

As jornadas flexíveis, ao mesmo tempo em que reduziram os desgastes das pesadas jornadas fixas, ampliaram sensivelmente 0 "tempo livre para o trabalho". Para os indivíduos, a perspectiva de tempo livre passou a ser condicionada às duras escolhas que devem cotidianamente fazer entre trabalho e vida pessoal. Caso se decida, em determinado momento, reduzir a dedicação ao trabalho para, por exemplo, dedicar-se mais tem-

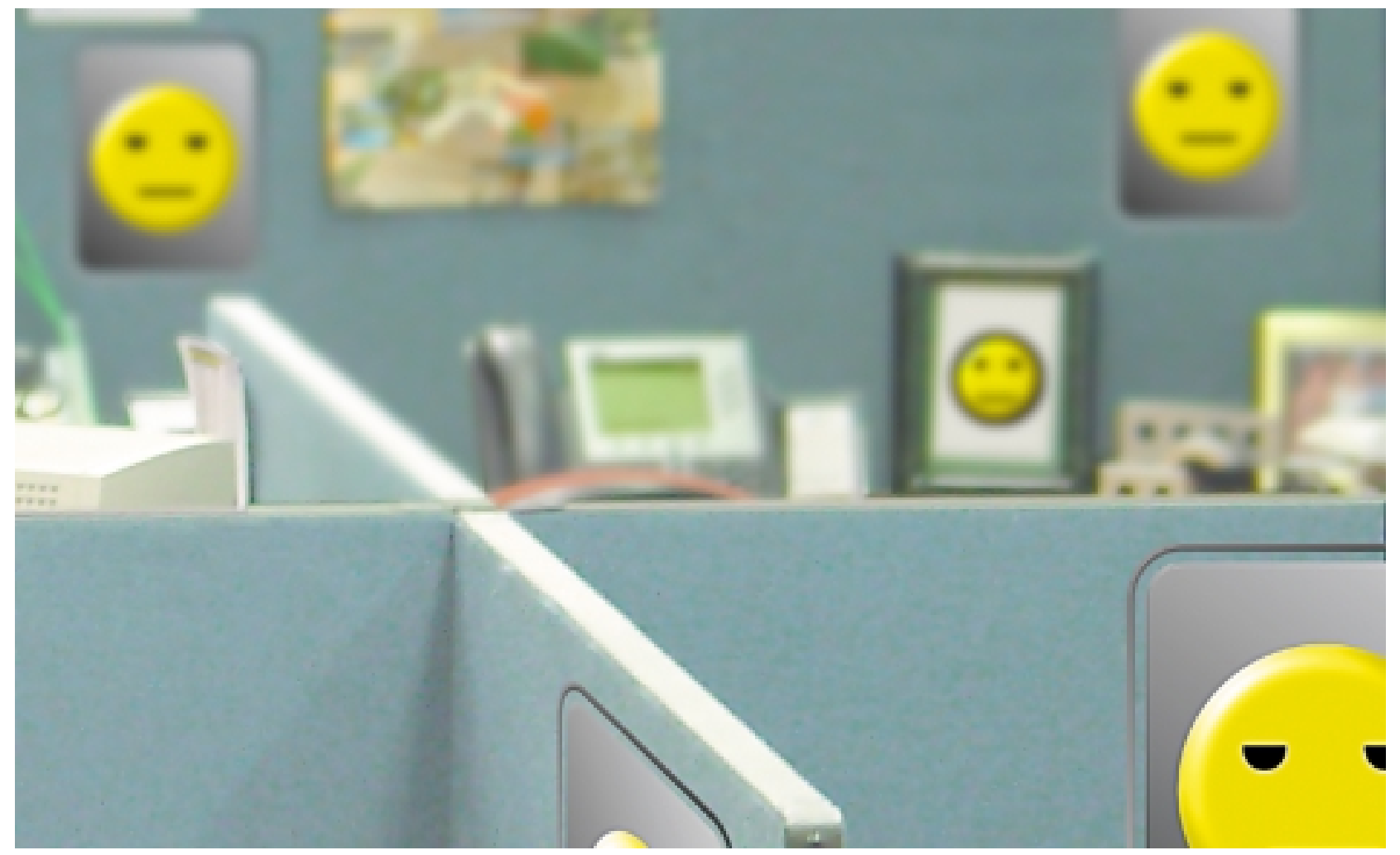


po ao contato com os filhos, o profissional certamente enfrentará pressões, sutis ou explícitas, e poderá ser visto como pouco comprometido ou pouco interessado no trabalho. Essa situação, presente no cotidiano, torna muito difícil o estabelecimento de limites e de prioridades - o que, em última instância, está na base de quadros de estresse e esgotamento emocional.

A soberania do indi víduo. 0 terceiro alvo de Mair é o trabalho em equipe, há tempos considerado como uma forma extremamente produtiva de organização das tarefas, pois (teoricamente) promove a sinergia e o enriquecimento de perspectivas. De fato, o trabalho em equipe vem sendo alvo de enormes investimentos em empresas dos mais variados setores. cionais" - argumenta que, em uma situação de trabal ho em grupo, o indivíduo pode "relaxar" - isto é, pode ter um desempenho inferior ao que teria se estivesse trabalhando sozinho. Esse comportamento é conhecido como "oportunismo social". O utro fenômeno importante do trabalho em grupo é o que Thompson chama de "contexto de norma de rebaixamento", que ocorre quando os indivíduos se submetem a um nível inferior de desempenho na situação grupal.

A última palavra. A liderança, nome brando dado às (nem sempre brandas) relações de poder presentes nas organizações, também não escapa das críticas de Mair. A quarta crítica que ela faz aos modernos dogmas da gestão de recursos humanos endereça-se aos processos coletivos de tomada de decisão, nos quais o líder se outorga o papel de "facilitador", se tanto. Segundo a autora, quem deve ter sempre a última palavra é o chefe, por mais que se pregue o contrário.

$\mathrm{Na}$ agência de Mair os funcionários tratam-se formalmente e pelo sobrenome, a hierarquia é clara e os chefes conduzem os negócios. A autora diz que não pretende que seu escritório seja como um

Para Mair, entretanto, o trabalho em equipe é um subterfúgio para que os funcionários pensem que os outros farão o trabalho por eles. Além disso, em sua opinião, o trabal ho em equipe padece de um outro mal, que é a necessidade de consenso. "Todos buscam o acordo em uma reunião. É claro que há sempre opiniões boas e ruins. Aí se perde tempo tentando selecionar as boas idéias ou aprimorar as ruins. No final, o resultado é meramente comum", declara Mair na revista Amanhã.

Há de fato algumas evidências de que o trabalho em equipe, em algumas circunstâncias, faz mais mal do que bem. Por exemplo, Leigh Thompson, em artigo publicado recentemente na RAE-executivo - "Desenvolvendo a criatividade dos grupos de trabalho organiza- lar, e os funcionários não precisam se esforçar para serem gentis ou eternamente agradáveis, contanto que respeitem padrões mínimos de convivência. Para ela, nada disso é incompatível com criatividade e produtividade. Segundo afirma: "O escritório não é uma festa para se divertir". Nele, os funcionários têm de trabal har.

Q uanto à hierarquia, crê a al emã que as atuais práticas de "equipes sem chefes" têm mais contribuído para desnortear as pessoas do que para lhes dar autonomia. Mair advoga que as hierarquias se tornaram o bichopapão de algumas corporações, levando a um contexto em que ninguém mais dá ordens claras e detalhadas. Com isso, surgiu um vácuo decisório povoado por empregados e chefes desorientados. 
O valor da crítica. Judith Mair pode ser vista como retrógrada em matéria de trabalho e disciplina. $\mathrm{Na}$ superfície, o que ela defende parece ser uma retomada das práticas gerenciais de 40 ou 50 anos atrás, ad equadas a um contexto de negócios e a um perfil social e cultural substancial mente diferentes dos atuais. Essa é certamente uma leitura possível, mas há outra: suas críticas podem também ser vistas como uma denúncia dos descaminhos e excessos ocorridos nas empresas nos últimos anos. A busca por patamares superiores de performance certamente trouxe val iosas inovações. Porém, junto a elas vieram dezenas de pseudo-inovações, idéias e práticas que se tornaram famosas e populares, mas que estão longe de constituir verdades universais.

Algumas décadas de culto a novidades provocaram efeitos colaterais temerários: a gestão de pessoas parece ter degenerado em um teatro de aparências cheio de efeitos pirotécnicos e vazio de consistência. Por trás de prêmios de responsabilidade social, ética, top of mind de recursos humanos, best place to work e muitos outros, persistem práticas retrógradas, desrespeito aos valores humanos e ações contra o meio social. Na mel hor hipótese, o discurso "ilustrado e moderno" dos gestores vai sinal izando mudanças que ainda estão por amadurecer. Em uma perspectiva mais real ista, o discurso torna-se entidade autônoma, servindo a propósitos políticos dos executivos e das empresas, constituindo uma fachada falsa para ruínas que mal se sustentam.

$N$ ão parece sensato desejar o retorno das condições de trabal ho de três décadas atrás, como propõe a executiva alemã. Porém, a desastrada tentativa de trazer corações e mentes, corpos e al mas para 0 ambiente de trabaIho pode estar causando efeitos inversos ao pretendido. E não apenas do ponto de vista da invasão da vida privada e do abuso psíquico dos indivíduos. Até mesmo do ponto de vista da funcionali idade al gumas práticas de gestão de recursos são decepcionantes. Mesmo que não se concorde com as soluções propostas por Judith Mair, não há como negar o mérito de suas críticas.

Pedro Fernando Bendassolli

Prof. de Psicologia na Universidade Paulista

Doutorando em Psicologia Social na USP

E-mail: pedrofernando@terra.com.br

\section{Regras de ouro de J udith Mair}

Em sua agência de publicidade, a executiva alemã criou regras que refletem sua concepção de trabalho e das relações humanas nos ambientes organizacionais.

\section{Sobre horários:}

- 0 expediente de trabalho vai de segunda a sexta, das $9 \mathrm{~h}$ às $18 \mathrm{~h}$

- 0 intervalo de almoço é limitado a meia hora: nesse período, deve-se providenciar um substituto

- Não se deve levar trabalho para casa

Sobre comportamento no trabalho:

- Os colegas de trabalho devem se tratar formalmente

- Ninguém precisa ser cordial ou gentil

- 0 mau humor pode ser tolerado, desde que não interfira no trabalho

- Os funcionários devem evitar risadas: 0 ambiente de trabaIho não deve ser um lugar divertido

\section{Sobre comunicação e distrações:}

- Conversas que não tenham a ver com o trabalho devem se resumir a, no máximo, cinco minutos

- Os celulares devem permanecer desligados no escritório

- A resposta a e-mails particulares deve ficar restrita aos intervalos

- Algumas palavras devem ser excluídas do vocabulário dos funcionários durante 0 expediente: workflow, deadline, briefing, brainstorming

- As reuniões devem ser curtas e objetivas: os assuntos tratados devem ser estritamente profissionais

Sobre controle e padronização:

- Sempre que possível, devem-se usar uniformes

- Todas as mesas devem estar em ordem no final do expediente 